\title{
Análisis de las principales tendencias aparecidas en TikTok durante el periodo de cuarentena por la COVID-19
}

\section{Analysis of the main trends published on TikTok during the quarantine period by COVID-19}

Francisco J. Olivares-García ${ }^{a}$, María Inés Méndez Majuelosa

a Departamento de Periodismo II, Facultad de Comunicación, Universidad de Sevilla, España

\section{Resumen}

Introducción: TikTok ha sido una de las redes sociales más usada por los usuarios más jóvenes durante el confinamiento por la COVID-19. Objetivo: Analizar las principales tendencias y vídeos publicados en la plataforma durante el periodo de cuarentena. Metodología: Se analizaron los contenidos y tendencias principales publicados en TikTok durante 25 días de confinamiento desde el 9 de abril al 3 de mayo de 2020. Se presenta un análisis cualitativo y cuantitativo de tendencias y retos virales relacionados con la COVID-19. Resultados: El estudio presenta un modelo de generación de contenidos y viralización de éstos totalmente novedoso, a partir de la presentación de unos contenidos que, aparentemente, no son útiles, no cambian el mundo ni la vida de los ciudadanos, y presentando productos vacíos y basados exclusivamente en la diversión y la imitación. Conclusiones: Frente a las acciones generadas en otras redes para la factura de mascarillas y pantallas, TikTok sólo ha aportado humor y entretenimiento. Sin embargo, bajo una aparente capa de superficialidad y frivolidad, se puede descubrir una foto fija de nuestra sociedad de puertas adentro.

Palabras clave: Narrativas; Redes Sociales; TikTok; Viralidad; Ciberadicción; Vídeo; Retos virales.

\begin{abstract}
Introduction: TikTok has been one of the most used social networks by younger users during confinement by COVID-19. Objective: To analyze the main trends and videos published on the platform during the quarantine period. Methodology: The main contents and trends published on TikTok were analyzed during 25 days of confinement from April 9 to May 3, 2020. It is presented a qualitative and quantitative analysis of viral trends and challenges related to COVID-19. Results: The study presents a completely new content generation and viralization model, based on the presentation of content that, apparently, is not useful, does not change the world or the lives of citizens, and presents empty products and based exclusively on fun and imitation. Conclusions: In front of the actions generated in other networks making face masks and protection screens, TikTok has only provided humor and entertainment. However, under an apparent layer of superficiality and frivolity, you can discover a picture of our society behind closed doors.
\end{abstract}

Keywords: Narratives; Social Networks; TikTok; Virality; Cyberdiction; Video; Viral challenges. 


\section{Introducción}

U na vez que la Organización Mundial de la Salud (OMS) declarara el brote de COVID-19 como pandemia, han sido muchas semanas las que los ciudadanos de los cinco continentes han permanecido sin salir de casa, lo que generó momentos para la reflexión y también momentos para el humor. En situaciones de crisis, las redes sociales se muestran especialmente útiles porque aumenta la comunicación entre los usuarios y se crea un sentimiento de comunidad, por ejemplo, grupos de intereses afines que aparecen en Facebook o Twitter con información útil para comunidades locales, personas que cosen mascarillas o fabrican protectores faciales con sus impresoras 3D para distribuir en hospitales. Sin embargo, TikTok no ha generado una comunidad que aporte algo útil durante el periodo de confinamiento, sino que se ha mantenido fiel a sus principios y se ha centrado en el humor y los vídeos intrascendentes.

En TikTok hay vídeos de temáticas muy variadas, pero el humor es la más usada por todo tipo de usuarios (Wang, 2020). Se verá en el apartado de resultados como los vídeos más vistos en TikTok durante estas semanas siguen siendo acciones divertidas y retos, sólo que ahora se van a ver inmersos en la temática del virus, la cuarentena y todo lo que esto conlleva.

Desde la aparición de las redes sociales en el año 2003 con Mypace, Internet se ha llenado de las aportaciones de millones de usuarios que buscaban socializar con otras personas intercambiando todo tipo de información, ideas y comentarios (Cohen-Almagor, 2011). En 2004 se crea Facebook, en 2005 YouTube y en 2006 Twitter. En 2019, 2.950 millones de personas participaron en alguna red social y la previsión para 2023 es de 3.430 millones (Clement, 2020).

TikTok es una red social de vídeo, de uso exclusivo en una aplicación para el móvil, creada en 2017 por la empresa china ByteDance. Según la consultora de aplicaciones móviles Sensor Tower TikTok se había convertido, en noviembre de 2019, en la tercera aplicación más descargada del sector de redes sociales, sólo por detrás de WhatsApp y Messenger (Chapple, 2019), lo cual se puede considerar el crecimiento más rápido de cualquier otra red social hasta la fecha, y la primera red social no creada en EE.UU. con presencia global relevante (Kemp, 2019).

Desde enero de 2020, TikTok ocuparía la quinta posición en número de usuarios, con 800 millones de usuarios activos, por detrás de WhatsApp, Facebook, Wechat e Instagram (Dawley, 2020), aunque la suma de TikTok y su gemelo chino Douyin podría superar fácilmente los mil millones de usuarios (Santirso, 2020).

El éxito de TikTok está en su funcionamiento, la forma de visualización y el tipo de contenidos, todo ello basado en una tecnología que une inteligencia artificial junto a la captación y grabación de imágenes de vídeo, dirigido a un usuario muy concreto. Por otra parte, la clave de ese éxito es la viralidad en un entorno de adolescentes, sobre la base de unos contenidos con una narrativa muy limitada en lo conceptual e ilimitada en los contenidos.

Las redes sociales tienen como objetivo que el usuario permanezca en la plataforma el mayor tiempo posible y, para ello, es fundamental que el contenido que se le ofrece sea de su agrado. TikTok fomenta la adicción a sus contenidos partir del modelo de la caja de Skinner en la que se pulsa la palanca una y otra vez en busca de recibir una recompensa (Peirano, 2019). La aplicación de algoritmos que personalizan el tipo de contenido que se muestra a cada usuario, en lugar de ampliar el conocimiento y los puntos de vista de las personas que participan en una red social, lo que consiguen es que se limiten y se hagan más radicales, ya que la plataforma sólo muestra contenido similar a nuestros gustos y opiniones, generando, lo que llamaba Pariser (2011) el filtro burbuja, porque el usuario termina aislado de cualquier otra ideología que no sea la propia.

TikTok es algo más que una aplicación de móvil para compartir vídeos cortos. Se trata de un espejo, de una forma de vida, de ver el mundo y la realidad que rodea a gran parte de sus usuarios y, también, de consumo para una comunidad de millones de jóvenes en todo el mundo (Herrman, 2019). En cuanto a la privacidad y la seguridad, la plataforma cuenta con una completa configuración de seguridad que incluye la privacidad, el control parental, el control del tiempo de uso, el coto a determinados términos de carácter sexual y xenófobo y, junto a lo anterior, la vigilancia del resto de los usuarios que pueden denunciar contenidos que consideren inadecuados (Rodríguez García \& Magdalena Benedito, 2016).

El éxito y el impacto de TikTok se basa, como se ha comentado anteriormente, en la simplicidad en su uso y en la viralidad de sus contenidos. Viralidad, a partir de la definición de Rushkoff (1996), es aquel contenido 
o pieza de información que se expande a través de las redes "infectándolas" con una suerte de "código ideológico" camuflado tras una apariencia informativa o de entretenimiento (Dafonte Gómez, 2015).

No existe aún, hoy en día, consenso acerca de qué factores hacen que un contenido se convierta en viral, aunque se están explorando diferentes elementos de carácter conceptual, narrativo y técnico. Laura Picazo (2016), desarrolla un catálogo de 90 items que se identifican en los vídeo que se convierten en virales en las redes sociales y que varían en función de varios factores, como las emociones, la necesidad de aceptación, hábitos de consumo y la transmisión de ideas y opiniones. Otros autores coinciden en señalar que se basa en la consecución de un beneficio, bien de carácter económico, informativo, emocional o propagandístico (Dafonte Gómez, 2015; Dobele, Lindgreen, Beverland, Vanhamme, \& van Wijk, 2007; Sarmiento Guede, de Esteban Curiel, \& Antonovica, 2017; Teixeira, 2012). En el caso de TikTok es, sin duda, el aspecto emocional el que se relaciona con la capacidad de proyección y la posibilidad de que una publicación se convierta en viral (Dobele et al. 2007). Por otra parte, la capacidad de las redes sociales para ser vehículos de transmisión de cultura, de cultura popular, está siendo ampliamente estudiada por investigadores del origen asiático (Zuo \& Wang, 2019). Dafonte Gómez (2014), en un análisis de publicidad viral, concluye que existe una correlación clara entre los estudios preliminares y los que obtiene en su investigación, siendo por tanto la transmisión de emociones y la necesidad de los usuarios de sentirse identificados y aceptados por la mayoría lo que convierte a un video o contenido publicitario en viral.

En este estudio se parte de la premisa de que el confinamiento de una gran parte de la población provocada por la COVID-19 ha afectado al contenido creado y distribuido en la plataforma. A partir de aquí se identificarán cuáles son los temas más valorados por los usuarios y aquellos vídeos que más atención han recibido, todo sin afectar al espíritu de la aplicación, que consiste mayoritariamente en la creación de vídeos divertidos sobre temas variados.

\section{Métodos}

El periodo de confinamiento a causa de la pandemia de la COVID-19 comenzó en España el domingo 15 de marzo con el Decreto de Estado de Alarma a nivel nacional. El análisis de visualizaciones para este trabajo comenzó el día 9 de abril cuando ya se llevaban 25 días de encierro y terminó el 3 de mayo, 25 días después, el día antes del comienzo de la fase 0 de la desescalada, lo que implicaba el final del periodo más riguroso de encierro doméstico. Durante este periodo se hicieron trece sesiones de toma de datos, una vez cada dos días.

Se han realizado dos análisis diferentes. El primero ha consistido en la descarga de los datos de visualización de 20 hashtags o etiquetas directamente relacionados con el tema de la cuarentena y el virus, entre el 9 de abril y el 3 de mayo de 2020, con toma de datos cada dos días para analizar la evolución de cada etiqueta.

Para la obtención de los 20 hashtags más populares se realizaron dos jornadas de observación de los vídeos relacionados con la temática coronavirus y cuarentena usando dos móviles y dos cuentas de nueva creación sin ningún tipo de historial de búsqueda previo, para que la obtención de los resultados fuese lo más neutra posible, sin interferencias y sin que el algoritmo afectase a los resultados. Durante estas dos jornadas se analizaron las etiquetas de los 50 vídeos con más vistas relacionados con el tema de estudio y, a partir de ahí, se elaboró un listado con las 20 etiquetas más repetidas, que son las que se usaron para hacer las gráficas de evolución cada dos días del número de visualizaciones. Se ha intentado representar en esta lista el mismo porcentaje de vídeos globales como locales, en este caso vídeos en castellano, que recibe un usuario medio.

En el segundo análisis, se han estudiado las cinco tendencias principales, durante ese mismo periodo temporal, relacionadas con la temática del estudio, investigando su origen, vídeos generados y seguidores entre otros factores. Para la realización del segundo trabajo, se han usado las tendencias que ofrece la plataforma en su apartado tendencias, donde aparecen los retos más seguidos por los usuarios. Se han seleccionado las tendencias con más visualizaciones que estuvieran directamente relacionadas con el tema del coronavirus y la cuarentena. El apartado tendencias de TikTok muestra aquellos vídeos, etiquetas o audios que más se están usando para crear nuevos vídeos o aquellos que más visualizaciones están teniendo. El contenido que aparece en esta sección no está afectado por el algoritmo que personaliza el contenido para cada usuario, por lo que se 
consideró que tenia las garantias suficientes de objetividad para que se usaran como base del estudio.

Los datos se cargaron directamente en una hoja de cálculo, que luego se ha tratado con Tableau, una aplicación para visualización de datos con la que se crearon las gráficas que ilustran este trabajo.

\section{Resultados}

\section{Análisis de los 20 hashtags más representativos}

A continuación, en la tabla 1 se puede observar los datos agregados de los resultados obtenidos en función de las etiquetas que tuvieron más visualizaciones durante el primer día de toma de datos.

Al final de la tabla 1 se puede observar cómo todas las etiquetas han progresado, aunque no todas lo han hecho en la misma medida, llegando a cambiar el orden original.

En la tabla 2 aparece el orden original y el orden final. En la mayoría de los casos no ha habido muchos cambios, pero es de destacar la etiqueta\#aplausosanitario que pasa de estar en el último puesto, al 18 , siendo además, como puede verse en la Tabla 3, la etiqueta que tiene un mayor crecimiento con un aumento porcentual del $225,81 \%$. También sube dos puestos \#yomequedoencasa, que pasa del 10 al 8 , con una subida del $121,43 \%$.

Entre las etiquetas que más bajan, habría que contabilizar \#virus que baja del puesto 8 al 11 y además es la que menos crece, con una subida de sólo el $27,78 \%$, seguida de \#conciertoenmibalcon que pasa del 15 al $17 \mathrm{y}$ solo sube el $29,96 \%$ (Tabla 4).

Tabla 1. Datos desde el 9 al 19 de abril de 2020.

\begin{tabular}{|c|c|c|c|c|c|c|}
\hline Hashtag & $09 / 04 / 2020$ & $11 / 04 / 2020$ & $13 / 04 / 2020$ & $15 / 04 / 2020$ & $17 / 04 / 2020$ & $19 / 04 / 2020$ \\
\hline coronavirus & 45.000 .000 .000 & 48.900 .000 .000 & 51.000 .000 .000 & 53.100 .000 .000 & 54.900 .000 .000 & 56.700 .000 .000 \\
\hline quarantine & 15.000 .000 .000 & 16.700 .000 .000 & 18.700 .000 .000 & 20.600 .000 .000 & 22.400 .000 .000 & 24.200 .000 .000 \\
\hline covid19 & 11.000 .000 .000 & 12.400 .000 .000 & 13.200 .000 .000 & 14.000 .000 .000 & 14.700 .000 .000 & 15.500 .000 .000 \\
\hline boredathome & 5.800 .000 .000 & 6.200 .000 .000 & 6.700 .000 .000 & 7.200 .000 .000 & 7.700 .000 .000 & 8.200 .000 .000 \\
\hline stayathome & 5.200 .000 .000 & 5.500 .000 .000 & 6.200 .000 .000 & 7.000 .000 .000 & 7.300 .000 .000 & 8.100 .000 .000 \\
\hline stayhome & 4.800 .000 .000 & 5.100 .000 .000 & 5.700 .000 .000 & 6.200 .000 .000 & 6.700 .000 .000 & 7.300 .000 .000 \\
\hline cuarentena & 4.400 .000 .000 & 4.900 .000 .000 & 5.500 .000 .000 & 6.100 .000 .000 & 6.600 .000 .000 & 7.200 .000 .000 \\
\hline virus & 1.800 .000 .000 & 1.900 .000 .000 & 2.000 .000 .000 & 2.000 .000 .000 & 2.100 .000 .000 & 2.100 .000 .000 \\
\hline covidn19 & 1.600 .000 .000 & 1.700 .000 .000 & 1.900 .000 .000 & 2.000 .000 .000 & 2.100 .000 .000 & 2.300 .000 .000 \\
\hline yomequedoencasa & 1.400 .000 .000 & 1.600 .000 .000 & 1.800 .000 .000 & 1.900 .000 .000 & 2.000 .000 .000 & 2.200 .000 .000 \\
\hline quedateencasa & 1.150 .000 .000 & 1.200 .000 .000 & 1.400 .000 .000 & 1.500 .000 .000 & 1.700 .000 .000 & 1.800 .000 .000 \\
\hline homeoutfits & 320.500 .000 & 341.300 .000 & 363.000 .000 & 381.900 .000 & 395.700 .000 & 411.300 .000 \\
\hline vecinos & 64.700 .000 & 68.800 .000 & 71.100 .000 & 73.600 .000 & 76.100 .000 & 78.600 .000 \\
\hline pandemia & 55.200 .000 & 58.800 .000 & 62.600 .000 & 69.100 .000 & 74.600 .000 & 79.100 .000 \\
\hline conciertoenmibalcon & 22.700 .000 & 23.300 .000 & 23.700 .000 & 24.200 .000 & 24.700 .000 & 25.100 .000 \\
\hline fitnessencasa & 19.600 .000 & 21.300 .000 & 22.700 .000 & 23.900 .000 & 25.600 .000 & 26.900 .000 \\
\hline lavatelasmanos & 17.900 .000 & 18.500 .000 & 21.300 .000 & 23.300 .000 & 25.600 .000 & 28.800 .000 \\
\hline aplausos & 10.500 .000 & 12.000 .000 & 12.500 .000 & 12.900 .000 & 13.200 .000 & 13.600 .000 \\
\hline epidemia & 10.700 .000 & 11.400 .000 & 12.000 .000 & 12.500 .000 & 13.000 .000 & 13.500 .000 \\
\hline aplausosanitario & 6.200 .000 & 7.100 .000 & 8.000 .000 & 8.600 .000 & 10.500 .000 & 11.300 .000 \\
\hline
\end{tabular}

Elaboración propia. 


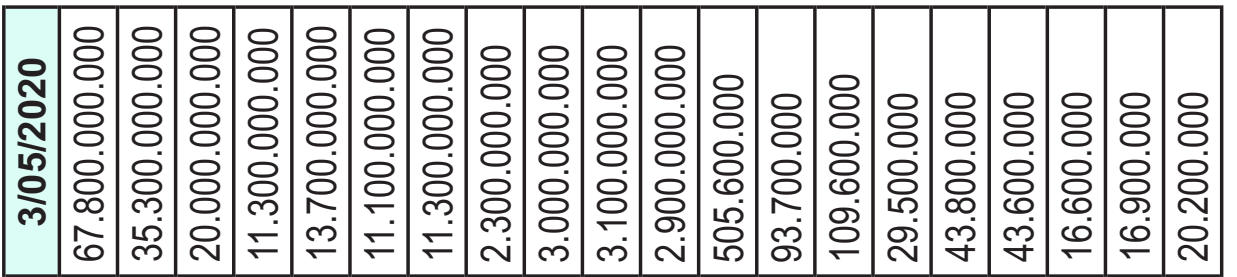

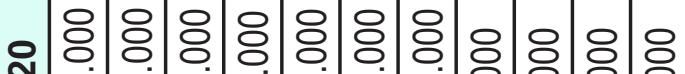

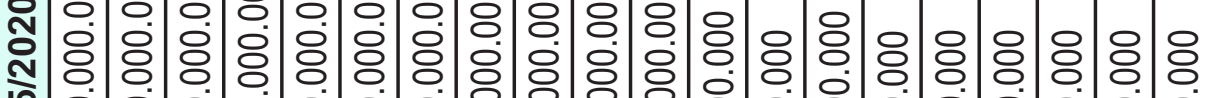
乍定

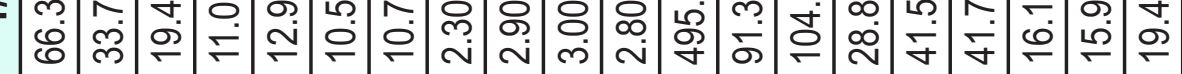

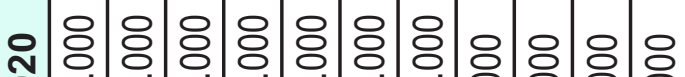

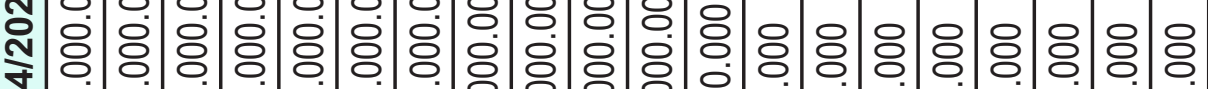
各 N

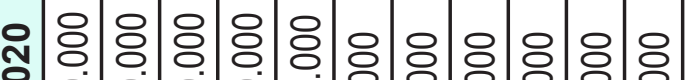

立 产

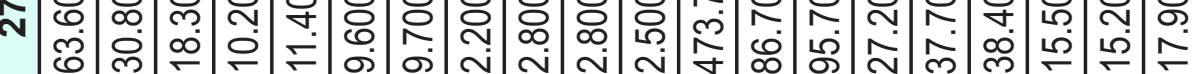

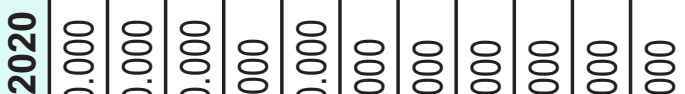

安 స్ đi

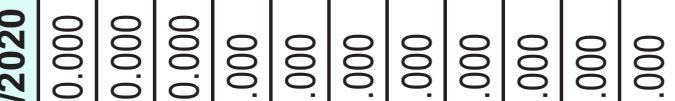

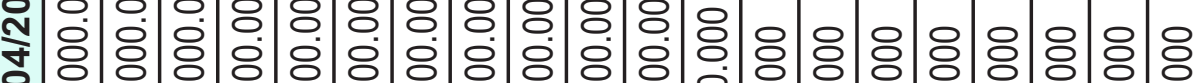

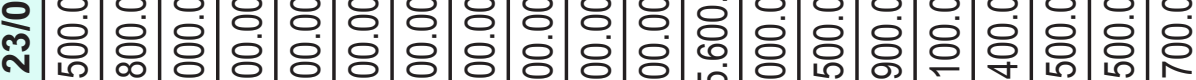

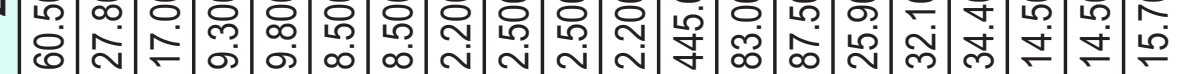

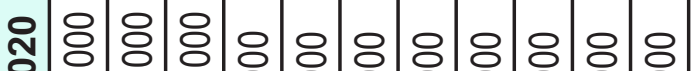

立

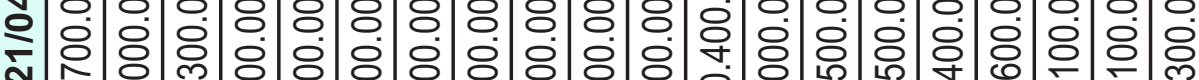
œ

$\overline{\bar{c}}$

$\frac{\Phi}{0}$

$\bar{\sim}$

ฮ으

옴

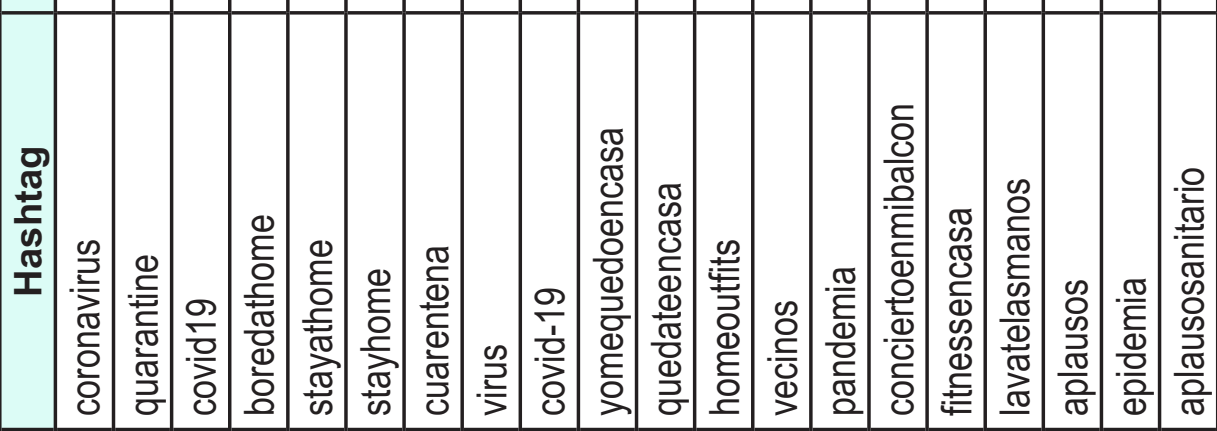


Tabla 3. Orden por número de visualizaciones al principio y al final de la toma de datos.

\begin{tabular}{|c|c|}
\hline $\mathbf{9 / 0 4 / 2 0 2 0}$ & $\mathbf{3 / 0 5 / 2 0 2 0}$ \\
\hline coronavirus & coronavirus \\
\hline quarantine & quarantine \\
\hline covid19 & covid19 \\
\hline boredathome & stayathome \\
\hline stayathome & boredathome \\
\hline stayhome & cuarentena \\
\hline cuarentena & stayhome \\
\hline virus & yomequedoencasa \\
\hline covid-19 & covid-19 \\
\hline yomequedoencasa & quedateencasa \\
\hline quedateencasa & virus \\
\hline homeoutfits & homeoutfits \\
\hline vecinos & pandemia \\
\hline pandemia & vecinos \\
\hline conciertoenmibalcon & fitnessencasa \\
\hline fitnessencasa & lavatelasmanos \\
\hline lavatelasmanos & conciertoenmibalcon \\
\hline aplausos & aplausosanitario \\
\hline epidemia & epidemia \\
\hline aplausosanitario & aplausos \\
\hline
\end{tabular}

Tabla 4. Porcentaje de crecimiento de cada etiqueta al final de la toma de datos.

\begin{tabular}{|c|c|}
\hline Hashtag & Porcentajes \\
\hline aplausosanitario & $225,81 \%$ \\
\hline stayathome & $163,46 \%$ \\
\hline cuarentena & $156,82 \%$ \\
\hline quedateencasa & $152,17 \%$ \\
\hline lavatelasmanos & $143,58 \%$ \\
\hline quarantine & $135,33 \%$ \\
\hline stayhome & $131,25 \%$ \\
\hline fitnessencasa & $123,47 \%$ \\
\hline yomequedoencasa & $121,43 \%$ \\
\hline pandemia & $98,55 \%$ \\
\hline boredathome & $94,83 \%$ \\
\hline covid-19 & $87,50 \%$ \\
\hline covid19 & $81,82 \%$ \\
\hline aplausos & $58,10 \%$ \\
\hline epidemia & $57,94 \%$ \\
\hline homeoutfits & $57,75 \%$ \\
\hline coronavirus & $50,67 \%$ \\
\hline vecinos & $44,82 \%$ \\
\hline conciertoenmibalcon & $29,96 \%$ \\
\hline virus & $27,78 \%$ \\
\hline & \\
\hline & \\
\hline & \\
\hline
\end{tabular}

Tablas: Elaboración propia. 
En las gráficas siguientes se presenta la comparación del crecimiento de la etiqueta \#aplausosanitario en comparación con la etiqueta \#virus, la que mayor crecimiento ha tenido, frente a la que menos ha crecido (Figura 1, Figura 2).

La etiqueta \#virus tiene un uso global, ya que es un término que se escribe igual es inglés. La evolución de la etiqueta se mueve entre los 1.800 y los 2.300 millones de visualizaciones que, aunque es un número considerable, apenas ha evolucionados durante todo el periodo analizado. Por contra, la etiqueta \#aplausosanitario muestra una curva de subida mucho acusada, especialmente a partir del 21 de abril, donde se observa un aumento de tres millones de vistas en dos días. Esta etiqueta es de uso exclusivo para España ya que hace referencia a los aplausos a las 20:00 horas, momento en que la población salía al balcón a aplaudir al personal sanitario.

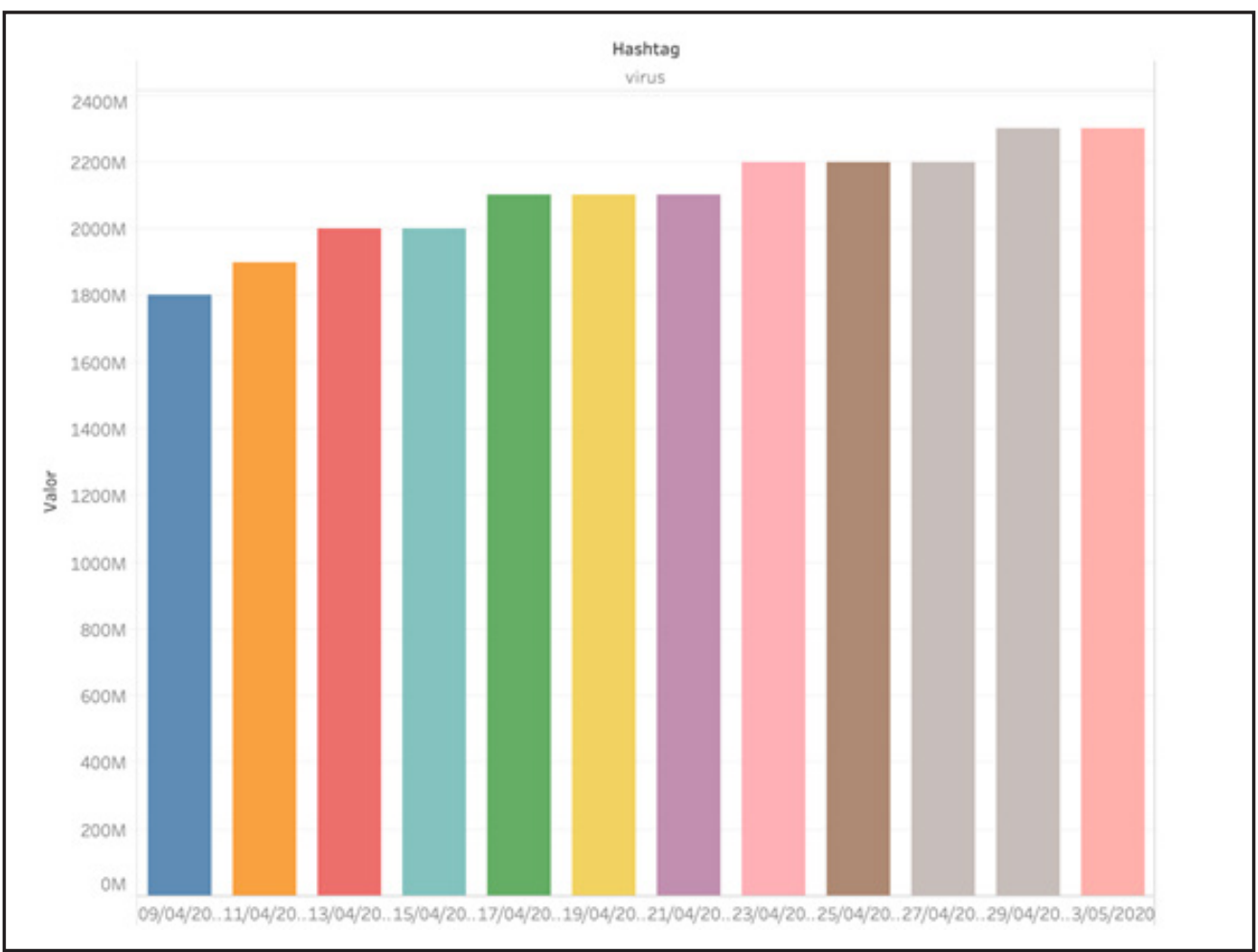

Figura 1. Evolución de la etiqueta \#virus. Elaboración propia con Tableau.

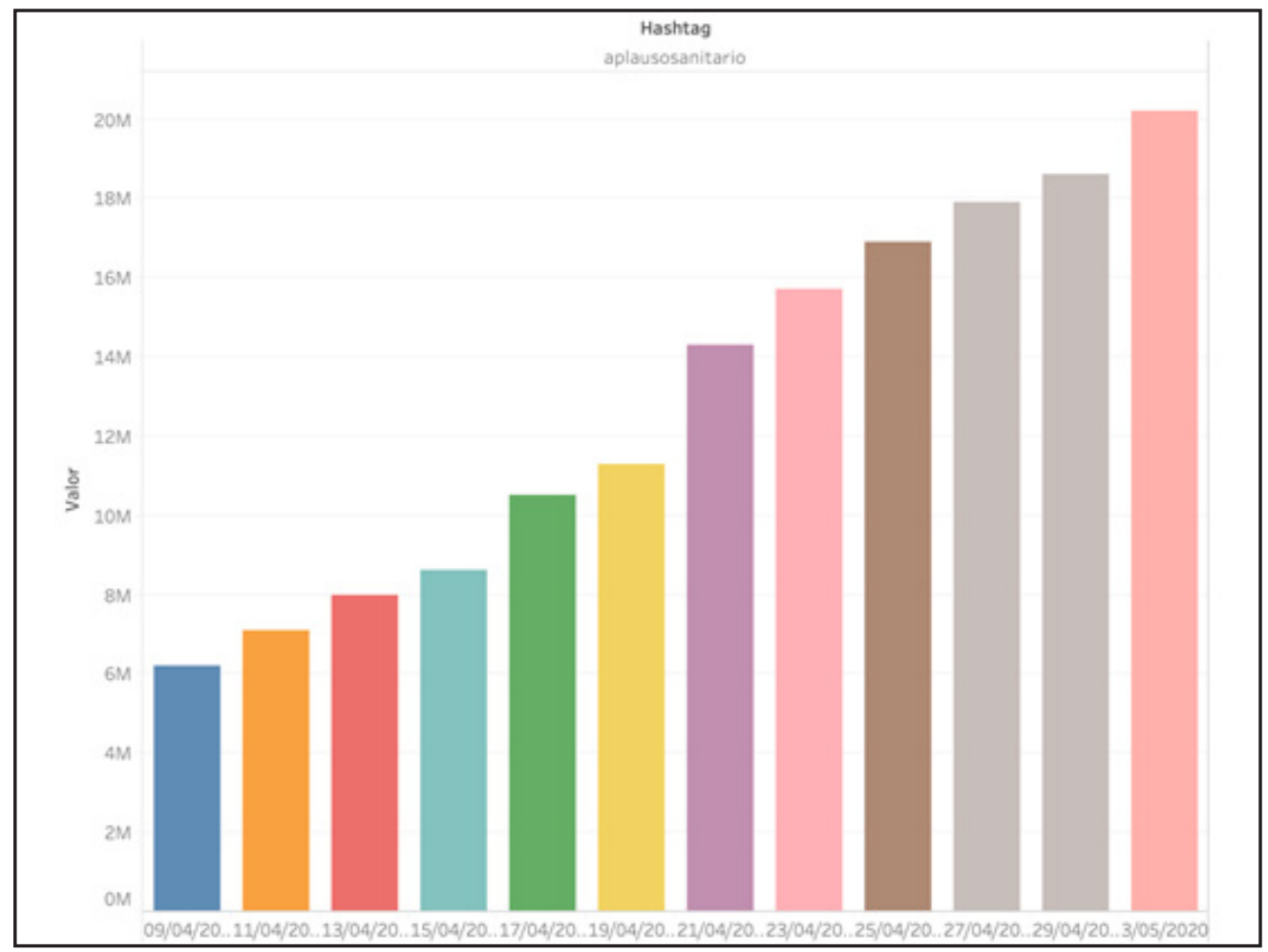

Figura 2. Evolución de la etiqueta \#aplausosanitario. Elaboración propia con Tableau. 
Análisis de las cinco tendencias más seguidas relacionadas con la temática del virus y la cuarentena

Se presenta, a continuación, un análisis de las tendencias relacionadas con el coronavirus o el confinamiento obtenidas de la lista de tendencias más importantes facilitadas por TikTok. Todos los datos de visualización son a fecha 3 de mayo de 2020.

\section{\#toiletpaperchalenge, 311,7 millones de visualizaciones}

Uno de los retos más seguidos durante este periodo de confinamiento, consiste en sujetar un rollo de papel higiénico por detrás de la cabeza, soltarlo y cogerlo al vuelo por debajo de las piernas. El día 3 de mayo de 2020, el vídeo se había visto 369.700 veces. @happyaslarry.co es un usuario con muy pocos seguidores, no llega a 3.000 y solo sigue a 20 usuarios de TikTok, lo que da una idea de la viralidad que puede alcanzar casi cualquier vídeo en la plataforma. Con el audio original se han subido 30.300 vídeos.

\section{\#levelup, 7.500 millones de visualizaciones}

No es un hashtag exclusivo del periodo de confinamiento, pero a partir de él se ha hecho popular durante estos días un reto también relacionado con el papel higiénico. El reto consiste en saltar, tanto personas como animales, una muralla de rollos de papel higiénico que va creciendo hasta que ya no se puede saltar. Se han encontrado 1,6 millones de videos subidos a TikTok que usan esta misma canción. En la propia cuenta de la artista encontramos un vídeo con fecha 3 de abril con un perro saltando barreras progresivas de papel higiénico.

\section{\#eligetupersonaje, 462,7 millones de visualizaciones}

Basado en un audio llamado Choose your character con el que se han subido 33.500 videos. El vídeo original pertenece a un usuario ruso llamado @ alextattoo que hizo esta peculiar acción, que se ha viralizado durante el periodo de cuarentena, el 26 de noviembre de 2018, y tiene más de dos millones de visualizaciones. Muchos usuarios influyentes están haciendo este reto, por ejemplo @diazpelayo, muy conocido por su aparición en programas de televisión de temática de moda y lifestyle, que tiene cuenta verificada con 90.000 seguidores. Hay que tener en cuenta que es uno de los famosos de televisión que inició su cuenta en TikTok ya durante la cuarentena, el 29 de marzo de 2020. Su vídeo de este reto ha sido visto 606.900 veces hasta el 3 de mayo de 2020 .

\section{\#boredathome, 11.400 millones de visualizaciones}

Este reto solo muestra una actividad aburrida en casa o la consecuencia de ese aburrimiento, lo que da pie a situaciones divertidas. Los vídeos más recientes usan un audio llamado Bored in the House del usuario Curtis Roach. El 27 de marzo se subió a YouTube una versión musical realizada por los raperos Tyga y el propio Curtis Roach, con cuatro millones de reproducciones.

\section{Discusión}

TikTok es una plataforma compleja, especialmente cuando el investigador intenta obtener datos para su análisis. Los vídeos no aparecen ordenados por fechas, no hay filtros para clasificar la información que se muestra y los pocos datos que se pueden obtener aparecen dispersos por la plataforma. En resumen, TikTok es una plataforma muy difícil de cuantificar. A la hora de aplicar una metodología de carácter cuantitativa y cualitativa a los contenidos de TikTok es preciso tener en cuenta que a medida que se profundizaba en algunos vídeos y en ciertas cuentas, el algoritmo de la aplicación iba refinando los resultados y cada vez ofrecía un contenido más similar al que se había marcado como favorito, el comportamiento de filtro burbuja, que en TikTok se presentaba de una forma muy acusada. Esta tendencia se hacía mayor si, además de lo anterior, se leían los comentarios o se entraba en cuentas de algún tiktoker, algo que el algoritmo interpretaba como interés por parte del usuario.

Desde el punto de vista de la investigación, crear un entorno objetivo para analizar lo que la plataforma ofrece es muy complejo porque existe el riesgo razonable de entrar dentro de la rutina del algoritmo y que lo que se muestre durante el tiempo de análisis y observación no tenga nada que ver con lo que está viendo un usuario medio. A modo de ejemplo, si se quiere analizar la incidencia del tema cuarentena y coronavirus en TikTok y se empieza a ver vídeos de esta temática, analizando los comentarios, las veces que se ha compartido un vídeo y las etiquetas que usa, TikTok va a darse cuenta muy rápidamente de que nos interesa este tema, por lo que va a empezar a reproducir continuamente este tipo de vídeos, que es posible que no se muestren tan a menudo al resto de usuarios. Esto mismo es lo que ocurre cuando se lee en la prensa que en TikTok sólo hay vídeos poco recomendables para los menores 0 que los ciudadanos estadounidenses están expuestos a ideologías comunistas. Todo esto es una posibilidad, siempre que un usuario se dedique a buscar este tipo de contenidos de forma recurrentemente. 
El uso del hogar como espacio de grabación es una práctica común, especialmente la creación de vídeos en habitaciones que no suelen verse en los vídeos ofrecidos en otras plataformas, como por ejemplo el cuarto de baño, uno de los sitios favoritos de los tiktokers para grabar sus vídeos (Lorenz, 2020).

Según se ha podido observar, no se puede hablar de una temática definida en la aplicación, pues hay tantos TikToks como usuarios tiene la plataforma y para unos usuarios TikTok es un sitio de bailes y coreografías, sin embargo, para otros es un sitio de recetas de cocina, de chistes o de cualquier otra actividad. En cualquier caso, el algoritmo siempre introducirá nuevos temas o los vídeos más populares del momento, con idea de aumentar el consumo y los intereses del usuario.

El siguiente paso para futuras investigaciones acerca del impacto y lo que representa TikTok para sus usuarios debe tener en cuenta cuáles son las causas y efectos psicológicos y socioculturales que guían el comportamiento de sus usuarios y la forma de manifestar de una manera más o menos creativa sus emociones y sentimientos ante el día a día, en situaciones de rutina o bien, de crisis social y sanitaria.

\section{Conclusiones}

En ninguno de los casos de tendencias o etiquetas analizados se han generado vídeos que supongan un beneficio de algún tipo para la comunidad y sin apenas libertad creativa. Sin embargo, los millones de vídeos generados se han convertido en una fotografía única de la manera en que millones de personas en todo el mundo han vivido una situación de casi dos meses de confinamiento

No se puede afirmar que el confinamiento haya disparado el consumo de vídeos en TikTok, porque la plataforma no facilita estos datos, pero través de los vídeos, tendencias y etiquetas que se han analizado durante un mes, sí que se constata que muchos de los usuarios, encerrados en sus casas, han centrado su actividad en la plataforma y en la repetición de los retos y tendencias relacionados con el coronavirus y la cuarentena.

En los vídeos que sus usuarios han subido a TikTok se han podido observar los sentimientos de todas esas personas, sus temores, su forma de vida, las relaciones entre los miembros de la familia. A través de las bromas y los momentos de humor, TikTok ha realizado un retrato de nuestra sociedad de puertas adentro.

\section{Referencias bibliográficas}

Chapple, C. (2019). TikTok Clocks 1.5 Billion Downloads on The App Store and Google Play. Recuperado de https://sensortower.com/blog/tiktokdownloads-1-5-billion

Clement, J. (2020). Number of social media users worldwide 2010-2021 | Statista. Recuperado de https://www.statista.com/statistics/278414/numberof-worldwide-social-network-users/

Cohen-Almagor, R. (2011). Internet history. International Journal of Technoethics, 2(2), 45-64. https://doi. org/10.4018/jte.2011040104

Dafonte Gómez, A. (2014). Claves de la publicidad viral: De la motivación a la emoción en los vídeos más compartidos - The Key Elements of Viral Advertising. From Motivation to Emotion in the Most Shared Videos. Revista Comunicar, 22(43), 199-207. https://doi.org/10.3916/C43-2014-20

Dafonte Gómez, A. (2015). Aproximación teórica al concepto de viralidad desde el punto de vista de comunicación aplicación y repercusiones en los contenidos publicitarios audiovisuales. En El nuevo diálogo social (pp. 601-612).

Dawley, S. (2020). Social Trends 2020 - Social Media Marketing \& Management Dashboard Hootsuite. Recuperado de https://hootsuite.com/ pages/social-trends-2020

Dobele, A., Lindgreen, A., Beverland, M., Vanhamme, J., \& van Wijk, R. (2007). Why pass on viral messages? Because they connect emotionally. Business Horizons, 50(4), 291-304. https://doi.org/10.1016/j. bushor.2007.01.004

Herrman, J. (2019, marzo 19). How TikTok Is Rewriting the World - The New York Times. The New York Times. Recuperado de https://www.nytimes. com/2019/03/10/style/what-is-tik-tok.html

Kemp, S. (2019). Digital 2019: Q4 Global Digital Statshot - DataReportal - Global Digital Insights. Recuperado de https://datareportal.com/ reports/digital-2019-q4-global-digital-statshot

Lorenz, T. (2020). We're All in the Bathroom Filming Ourselves. The New York Times. Recuperado de https://www.nytimes.com/2020/01/23/style/tik-tokbathrooms.html 
Pariser, E. (2011). The Filter Bubble: What The Internet Is Hiding From You. Penguin UK.

Peirano, M. (2019). El enemigo conoce el sistema: manipulación de ideas, personas e influencias después de la economía de la atención. Debate.

Picazo Sánchez, L. (2016). Narrativas del vídeo viral. 99 claves para un contenido contagioso. Mediaciones Sociales, O(15), 115-132. https://doi.org/10.5209/ meso. 54546

Rodríguez García, L., \& Magdalena Benedito, J. R. (2016). Perspectiva de los jóvenes sobre seguridad y privacidad en las redes sociales. Revista ICONO14 Revista científica de Comunicación y Tecnologías emergentes, 14(1), 24-49. https:// doi.org/10.7195/ri14.v14i1.885

Rushkoff, D. (1996). Media virus!: hidden agendas in popular culture. Ballantine Books.

Santirso, J. (2020, enero 18). El lado oscuro de TikTok, el rey chino de los vídeos relámpago | Economía | El País. El País. Recuperado de https://elpais.com/economia/2020/01/16/ actualidad/1579191053_051932.html

Sarmiento Guede, J. R., de Esteban Curiel, J., \& Antonovica, A. (2017). La comunicación viral a través de los medios sociales: análisis de sus antecedentes. Revista Latina de Comunicación Social, 72, 6986. https://doi.org/10.4185/RLCS, 72-2017-1154

Teixeira, T. S. (2012, March). The New Science of Viral Ads. Harvard Business Review. Recuperado de https://hbr.org/2012/03/the-new-science-of-viral-ads

Wang, Y. (2020). Humor and camera view on mobile short-form video apps influence user experience and technology-adoption intent, an example of TikTok (DouYin). Computers in Human Behavior, 110. https://doi.org/10.1016/j.chb.2020.106373

Zuo, H., \& Wang, T. (2019). Analysis of Tik Tok User Behavior from the Perspective of Popular Culture. Frontiers in Art Research, 1(3), 1-05. https://doi. org/10.25236/FAR.20190301 